\title{
RANCANG ULANG MESIN FERMENTASI ROTI DENGAN PENDEKATAN REKAYASA NILAI DAN ANALITICAL HIRARCHY PROCESS DIGUNAKAN SEBAGAI PEMBOBOTAN ALTERNATIVE
}

\author{
Hakam Muzakki \\ Dosen Fakultas Teknik Universitas Trunojoyo Madura \\ muzakki.h@gmail.com
}

\begin{abstract}
Abstrak
Dalam makalah ini dibahas mengenai rekayasa ulang mesin fermentasi dengan beberapa alternatif rancangan dan komponen untuk meningkatkan kinerja dari mesin, serta juga dibahas mengenai analisa biaya dari masing-masin rancangan sehingga harga dari mesin yang baru lebih terjangkau oleh home industri. Agar pembahasan makalah ini lebih fokus maka studi kasus dilakukan pada perusahaan home industri roti UD XYZ di kabupaten Bangkalan.

Metode dan teknik yang digunakan dalam merancang ulang mesin fermentasi roti pada home industry UD XYZ dengan pendekatan rekayasa nilai, sistem pakar dipergunakan untuk langkah informasi, langkah kreative, dan penetuan kriteria dan pembobotan. fishbone diagram dan Pareto diagram dipergunakan untuk tahap identifikasi dan kreative. AHP dipergunakan untuk pembobotan dan penentuan kriteria atau alternatif.

Alternatif 1 merupakan rancangan yang paling baik dibandingkan dengan alternatif-alternatif yang lain, dan mempunyai kinerja hampir dua kali lipat dibandingkan dengan mesin awal.
\end{abstract}

Kata kunci : mesin fermentasi roti, rekayasa nilai, analitical hyrarchy process

\begin{abstract}
This paper is discussed about redesign fermentation machine by some design alternatives and componens to improve performance of machine, it is also explained about cost analysis each design so the price of machine is cheaper so the home industries can buy it. To focuse, this paper has token in a home indutry. It is UD XYZ in Bangkalan distric.

Teknique and method has been used to redesign fermentation cake at the home industry UD XYZ by value engineering, expert system is used to information stage, creative stage, and criteria decission stage and wight. Fishbone diagram and pareto diagram are used to identification and creative stage. AHP is used to wight and creative or alternative decission.

Alternative 1, one of some alternative, is the best alternative when compared with another and it has more than the old machine.
\end{abstract}

Keyword : baerd fermentation machine, value engineering, analitical hyrarchy process

\section{PENDAHULUAN}

Usaha kecil menengah roti di kabupaten Bangkalan mengalami perkembangan yang sangat pesat sehingga menimbulkan kompetisi yang semakin ketat. Home industri roti agar bisa bersaing harus meningkatkan kualitas dan memperbaiki harga jual produk, saat ini mayoritas dari home industri masih menggunakan sistem dan fasilitas produksi yang masih tradisional.

Proses produksi roti yang masih tradisional yaitu proses produksi yang masih menggunakan lampu pijar pada proses fermentasi adonan, proses fermentasi menggunakan lampu pijar ini mempunyai beberapa kendala salah satunya penyebaran peningkatan temperatur yang tidak merata sehingga kualitasnya kurang maksimal. Ada beberapa Home Industri Roti yang telah menggunakan mesin fermentasi tetapi kerja dari mesin fermentasi yang telah ada masih ada beberapa kelemahan, selain harga mesinnya yang mahal biaya operasional masih cukup tinggi.

Dalam makalah ini dibahas mengenai rekayasa ulang mesin fermentasi dengan beberapa alaternatif rancangan dan komponen untuk meningkatkan kinerja dari mesin, serta juga dibahas mengenai analisa 
biaya dari masing-masin rancangan sehingga harga dari mesin yang baru lebih terjangkau oleh home industri. Agar pembahasan makalah ini lebih fokus maka studi kasus dilakukan pada perusahaan home industri roti UD XYZ di kabupaten Bangkalan.

Untuk mengoptimalkan hasil perancangan ulang mesin fermentasi ini digunakan pendekatan rekayasa nilai (value Engineering), Orginilitas dari makalah yaitu dibahas mengenai rancang ulang mesin fermentasi adonan roti dengan pendekatan rekayasa nilai, Analytical Hyrarchy Process (AHP) dipergunakan untuk menentukan bobot dari beberapa alternative rekayasa, dan biaya juga dibahas dalam makalah ini.

\section{METODE PENELITIAN}

\section{Subject}

Mesin fermentasi menjadi bahasan utama dalam makalah ini terutama mesin fermentasi yang digunakan UD $\mathrm{XYZ}$ dalam proses produksi. Mesin fermentasi tersebut masih memiliki kelemahan yaitu penyebaran panas yang dihasilkan belum merata sehingga berdampak pada kualitas produk, biaya operasional masih cukup tinggi yang berdampak pada harga produk, dan biaya pengadaan mesin cukup mahal bila dibandingkan dengan kapasitas dan fungsinya.

\section{Rekayasa Nilai (Value Engineering)}

Rekayasa nilai, analisa nilai atau manajemen nilai adalah salah satu dari metode atau teknik yang sangat penting dalam manajemen proyek, yang bisa membantu mendifinisikan sistem secara langsung pada sistem analisa fungsi, peralatan, fasilitas, dan kebutuhan untuk kegunaan dari pencapaian fungsi-fungsi yang penting pada total biaya paling rendah, pencapaian pemenuhan kebutuhan, kesesuaian, kualitas, perawatan, kaidah norma, keselamatan dan kendala kebakaran (Houshang Taghizadeh, et. al, 2012), rekayasa nilai adalah sebuah metode yang berfungsi bagi seluruh bidang keilmuan untuk mencapai nilai tertinggi setiap bagian kebijakan yang berhubungan dengan keuangan atau metode khusus untuk mengoptimal dan penghematan energi, penelitan yang telah dilakukan oleh Habibollah Najafi, dan Amir Abbas Yazdani, 2011, rekayasa nilai dipergunakan untuk menjadwalkan kegiatan-kegiatan operasional dan produksi. Rekaya nilai dipergunakan untuk mencari cara yang efektive untuk menekan biaya proyek konstruksi (Boo Young Chung, et. al. 2009), dengan rekayasa nilai bisa membantu seluruh departemen untuk menentukan skema terbaik agar kebutuhan konsumen terhadap produk bisa terpenuhi dengan biaya yang rendah, (Chougule Mahadeo Annappa and Kallurkar Shrikant Panditrao, 2013), rekaya nilai dipergunakan untuk mengoptimalkan produksi perabot rumah di industri perabot. merancang kemampuan produk agar bisa diterima oleh konsumen dengan cara membandingkan fungsi produk dengan kebutuhan dan keinginan konsumen (Chougule M.A and Kallurkar, 2012), analisa biaya merupakan salah satu pertimbangan dalam perancangan produk, (Houshang Taghizadeh, et. al, 2012), rekaya nilai diguanakan oleh Amit Sharma, et. al, 2011, untuk meningkatkan kualitas, fungsi dan harga produk, Rekaya nilai yang dipadukan dengan metode lain dipergunakan untuk memastikan perbaikan kualitas dalam merancang sebuah produk (Jahangir Y. F, and Noraddin. H, 2012), reyasa nilai dipergunakan untuk melakukan rancang ulang mesin fermentasi roti yang dijadikan bahasan utama dalam makalah ini, dan juga sebagai salah satu orsinilitas bahasan. Tahapan-tahapan dalam rekayasa nilai yaitu: Orientasi dan persiapan, informasi, analisa fungsi dan biaya, inovasi dan kreative, evaluasi dari alternative, serta penerapan dan pengawasan (J. Cerqueiro et al, 2011), paduan dari beberapa metode dan teknik rekayasa nilai (VE), Quality Function Deployment (QFD) dan Design for Manufacture and Assembly (DFMA) digunakan oleh Jahangir Yadollhi Farsi dan Noraddin Hakiminezhad 2012, 
dalam merancang produk, pada tahapan evaluasi dari alternative digunakan Analytic Hierarchy Process (AHP) untuk pembobotan beberapa alternative.

\section{Analytic Hierarchy Process (AHP)}

\section{HASIL DAN PEMBAHASAN}

\section{Langkah pertama Identifikasi dan} informasi

Langkah identifikasi dan informasi, pada langkah pertama ini dibahas mengenai identifiasi terhadap mesin fermentasi yang telah dimiliki oleh industri rumah tangga UD. XYZ. Beberapa tools digunakan untuk proses identifikasi, pertama digunakan sistem pakar, kedua digunakan fishbone diagram dan kemudian diagram pareto.

\section{Proses identifikasi dengan sistem pakar}

Para operator mesin tersebut sebanyak 3 (tiga) orang yang dianggap sudah benarbenar faham dan mengerti kelebihan dan kekurangan dari mesin yang ada. Pembahasan mengenai kelebihan dan kekurangan mesin yang telah ada dilakukan beberapa kali dan diantara pembahasan didatangkan seorang yang dianggap mahir dengan sistem dan fungsi kerja dari beberapa mesin fermentasi yang terbaru.

Dari hasil pembahasan para pakar yang ada disimpulkan beberapa kelebihan dan kelemahan mesin fermentasi milik UD. XYZ.

Beberapa kelebihan dari mesin fermensi yang ada yaitu :

- Proses pengembangan roti lebih cepat

- Kadar air dalam roti menurun

- Kualitas roti lebih baik jika dibandingkan secara manual

- Suhu dalam ruang fermentasi lebih konstan

Beberapa kelemahan dari mesin tersebut yaitu:

- Biaya operasional tinggi

- Distribusi panas pada temperatur ruang fermentasi tidak merata
- Biaya perawatan mesin dan alat bantu tinggi

- Investasi untuk pengadaan mesin sangat mahal.

\section{Fishbone diagram}

Beberapa kelemahan dan kelebihan telah ditentukan oleh beberapa orang yang diaggap pakat, dari kekurangan yang ada dijadikan dasar untuk mencari kelemahan dari rancangan yang ada. Dengan fishbone diagram ditentukan penyebab kelemahan dari mesin tersebut terutama dalam rancangan (design) dan komponennya.

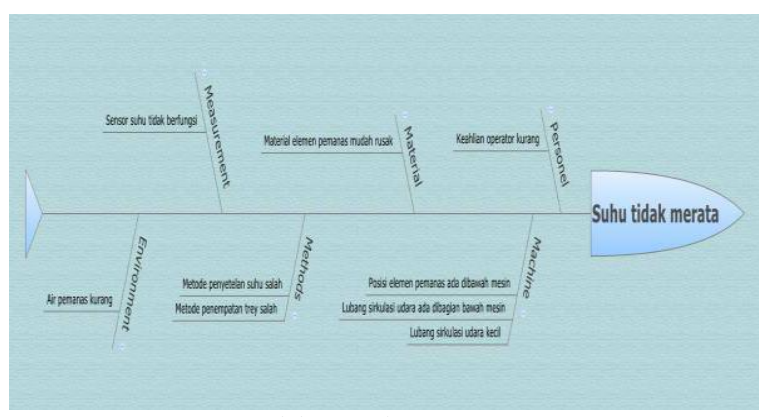

Gambar 1 Fishbone diagram biaya perawatan

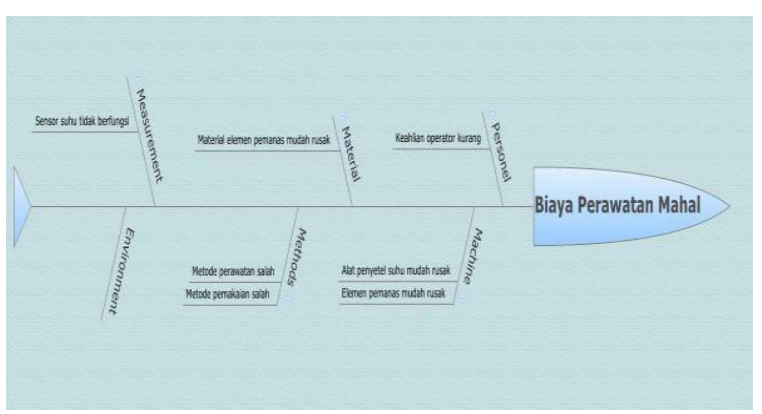

Gambar 2 Fishbone diagram suhu tidak merata

\section{Histogram}

Dengan histogram (Arazi Idrus and Christiono Utomo, 2010) diharapkan dapat mengetahui pengaruh pemerataan suhu, waktu proses, konsumsi listrik, dan biaya yang dibutuhkan pada mesin yang lama, dan dibandingkan dengan beberapa alternative rancangan yang baru. 

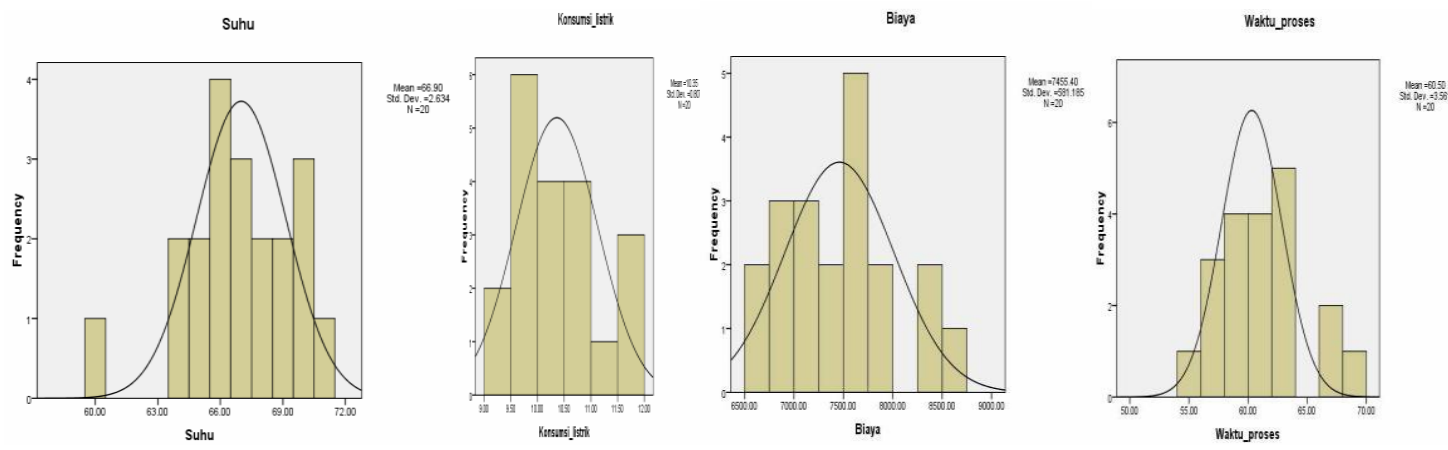

Gambar 3 Histogram mesin fermentasi yang lama

\section{Langkah kreatif}

Berdasarkan langkah satu didapat beberapa alternative rancangan mesin yang baru dengan beberapa modivikasi sumber energi, sistem dan komponen kesetabilan suhu, sistem dan komponen distribusi suhu. Dari beberapa kombinasi sistem dan komponen mesin sebagai rekayasa alternative mesin yang baru maka ada beberapa alternatif mesin yang baru yaitu :

1. Alternatif 1 : gas, sistem otomatis, tanpa pipa

2. Alternatif 2 : gas, sistem otomatis, dengan 4 pipa

3. Alternatif 3 : gas, sistem otomatis, dengan 6 pipa

4. Alternatif 4 : gas, tidak otomatis, tanpa pipa

5. Alternatif 5 : gas, tidak otomatis, dengan 4 pipa

6. Alternatif 6 : gas, tidak otomatis, dengan 6 pipa

7. Alternatif $7:$ mitan, ada sistem otomatis, tanpa pipa

8. Alternatif $8:$ mitan, ada sistem otomatis, dengan 4 pipa

9. Alternatif $9:$ mitan, ada sistem otomatis, dengan 6 pipa

10.Alternatif 10: mitan, tidak otomatis, tanpa pipa

11.Alternatif 11: mitan, tidak otomatis, dengan 4 pipa

12.Alternatif 12: mitan, tidak otomatis, dengan 6 pipa

13.Alternatif 13: listrik dan gas, ada sistem otomatis, tanpa pipa

14.Alternatif 14: listik dan gas, ada sistem otomatis, dengan 4 pipa

15.Alternatif 15: listrik dan gas, ada sistem otomatis, dengan 6 pipa
16. Alternatif 16: listrik dan gas, tidak otomatis, tanpa pipa

17.Alternatif 17: listrik dan gas, tidak otomatis, dengan 4 pipa

18. Alternatif 18: listrik dan gas, tidak otomatis, dengan 6 pipa

Dari hasil diskusi para pakar ditentukan enam alternative yang menjadi prioritas:

1. Alternatif 1 : gas, ada sistem otomatis tanpa pipa

2. Alternatif 3 : gas, ada sistem otomatis dengan 6 pipa

3. Alternatif 7 : mitan, ada sistem otomatis tanpa pipa

4. Alternatif 8 : mitan, ada sistem otomatis dengan 4 pipa

5. Alternatif 13: listrik dan gas, ada sistem otomatis tanpa pipa

6. Alternatif 15: listrik dan gas, ada sistem otomatis dengan 6 pipa

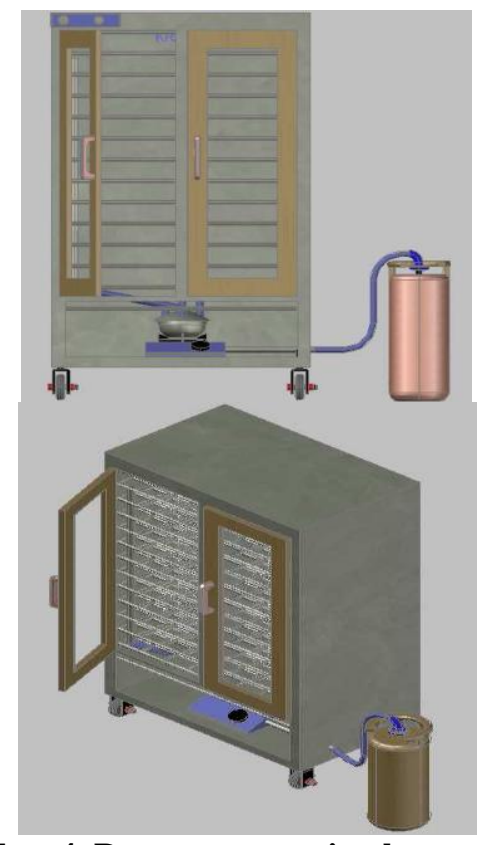

Gambar 4 Rancangan mesin alternative 15 


\section{Langkah Analisa}

Dalam makalah ini dibahas analisa biaya untuk setiap alternative rancangan mesin, bagian-bagian yang menimbulkan sebagai dasar penentuan besarnya biaya yaitu biaya komponen mesin, biaya komsumsi energi, dan biaya perwatan.

Tabel 1 Perincian biaya mesin saat ini digunakan

\begin{tabular}{cccc}
\hline $\begin{array}{c}\text { Biaya investasi } \\
(\text { mesin })(\mathrm{Rp})\end{array}$ & $\begin{array}{c}\text { Ongkos Energi } \\
(\mathrm{Rp})\end{array}$ & $\begin{array}{c}\text { Ongkos Perawatan } \\
(\mathrm{Rp})\end{array}$ & $\begin{array}{c}\text { Total Biaya } \\
(\mathrm{Rp})\end{array}$ \\
\hline 25.000 .000 & 7.450 & 20.000 & 25.027 .450 \\
\hline
\end{tabular}

Tabel 2 Tabel perincian penghematan biaya alternatif 1

\begin{tabular}{|c|c|c|c|c|}
\hline $\begin{array}{c}\text { Biaya } \\
\text { Investasi/mesin }(\mathrm{Rp})\end{array}$ & \multicolumn{2}{|c|}{$\begin{array}{c}\text { Biaya komponen } \\
\text { otomatis Listrik (Rp) }\end{array}$} & $\begin{array}{l}\text { Biaya Elemen } \\
\text { listrik (Rp) }\end{array}$ & $\begin{array}{c}\text { Efisiensi Biaya } \\
(\mathrm{Rp})\end{array}$ \\
\hline 25.000 .000 & \multicolumn{2}{|c|}{4.500 .000} & 500.000 & 20.000 .000 \\
\hline \multicolumn{5}{|c|}{ Tabel 3 Tabel perincian total biaya alternatif 1 (Energi Gas sistem otomatis tanpa Pipa) } \\
\hline $\begin{array}{l}\text { Efisiensi biaya } \\
\text { (Rp) }\end{array}$ & $\begin{array}{c}\text { Biaya } \\
\text { Energi/hari } \\
(\mathrm{Rp})\end{array}$ & $\begin{array}{c}\text { Biaya } \\
\text { Perawatan/hari } \\
(\mathrm{Rp})\end{array}$ & $\begin{array}{c}\text { Biaya } \\
\text { Komponen } \\
(\mathrm{Rp})\end{array}$ & $\begin{array}{l}\text { Total Biaya } \\
\qquad(\mathrm{Rp})\end{array}$ \\
\hline 20.000 .000 & 5.517 & 24.000 & 2.000 .000 & 22.029 .517 \\
\hline
\end{tabular}

Tabel 4 Tabel perincian total reduksi cost Alternatif 3

\begin{tabular}{cccc}
\hline $\begin{array}{c}\text { Biaya } \\
\text { Investasi/mesin }(\mathrm{Rp})\end{array}$ & $\begin{array}{c}\text { Biaya komponen } \\
\text { otomatis Listrik (Rp) }\end{array}$ & $\begin{array}{c}\text { Biaya Elemen } \\
\text { listrik (Rp) }\end{array}$ & $\begin{array}{c}\text { Efisiensi biaya } \\
(\mathrm{Rp})\end{array}$ \\
\hline 25.000 .000 & 4.500 .000 & 500.000 & 20.000 .000 \\
\hline
\end{tabular}

Tabel 5 Tabel perincian total biaya Alternatif 3

\begin{tabular}{ccccc}
\hline $\begin{array}{c}\text { Efisiensi biaya } \\
(\mathrm{Rp})\end{array}$ & $\begin{array}{c}\text { Biaya } \\
\text { Energi/hari } \\
(\mathrm{Rp})\end{array}$ & $\begin{array}{c}\text { Biaya } \\
\text { Perawatan/hari }\end{array}$ & $\begin{array}{c}\text { Biaya } \\
\text { komponen }\end{array}$ & Total Biaya \\
\hline 20.000 .000 & 5.517 & 24.000 & 2.378 .000 & 22.029 .517 \\
\hline
\end{tabular}

Tabel 6 Tabel perincian total reduksi cost Alternatif 7

\begin{tabular}{|c|c|c|c|}
\hline $\begin{array}{c}\text { Biaya } \\
\text { Investasi/mesin }(\mathrm{Rp})\end{array}$ & $\begin{array}{c}\text { Biaya komponen } \\
\text { otomatis Listrik (Rp) }\end{array}$ & $\begin{array}{l}\text { Biaya Elemen } \\
\text { listrik }(\mathrm{Rp})\end{array}$ & $\begin{array}{l}\text { Efisiensi biaya } \\
(\mathrm{Rp})\end{array}$ \\
\hline 25.000 .000 & 4.500 .000 & 500.000 & 20.000 .000 \\
\hline \multicolumn{4}{|c|}{ Tabel 7 Tabel perincian total biaya Alternatif 7} \\
\hline $\begin{array}{l}\text { Efisiensi biaya } \\
\text { (Rp) }\end{array}$ & $\begin{array}{cc}\text { Biaya Energi/ } & \text { Biaya Perawatan/ } \\
\text { Hari }(\mathrm{Rp}) & \text { hari }(\mathrm{Rp})\end{array}$ & $\begin{array}{c}\text { Biaya } \\
\text { Komponen (Rp) }\end{array}$ & $\begin{array}{l}\text { Total Biaya } \\
(\mathrm{Rp})\end{array}$ \\
\hline 20.000 .000 & 26.000 & 1.350 .000 & 21.382 .292 \\
\hline \multicolumn{4}{|c|}{ Tabel 8 Tabel perincian total reduksi cost Alternatif 8} \\
\hline $\begin{array}{c}\text { Biaya } \\
\text { Investasi/mesin (Rp) }\end{array}$ & $\begin{array}{c}\text { Biaya komponen } \\
\text { otomatis Listrik }(\mathrm{Rp})\end{array}$ & $\begin{array}{l}\text { Biaya Elemen } \\
\text { listrik (Rp) }\end{array}$ & $\begin{array}{l}\text { Efisiensi biaya } \\
(\mathrm{Rp})\end{array}$ \\
\hline 25.000 .000 & 4.500 .000 & 500.000 & 20.000 .000 \\
\hline
\end{tabular}

Tabel 9 Tabel perincian total biaya Alternatif 8

\begin{tabular}{ccccc}
\hline $\begin{array}{c}\text { Efisiensi biaya } \\
(\mathrm{Rp})\end{array}$ & $\begin{array}{c}\text { Biaya Energi/ } \\
\text { Hari }(\mathrm{Rp})\end{array}$ & $\begin{array}{c}\text { Biaya Perawatan/ } \\
\text { hari }(\mathrm{Rp})\end{array}$ & $\begin{array}{c}\text { Biaya } \\
\text { Komponen }(\mathrm{Rp})\end{array}$ & $\begin{array}{c}\text { Total Biaya } \\
(\mathrm{Rp})\end{array}$ \\
\hline 20.000 .000 & 6.292 & 26.000 & 1.602 .000 & 21.382 .292 \\
\hline
\end{tabular}


Tabel 10. Tabel perincian total biaya Alternatif 13

\begin{tabular}{|c|c|c|c|}
\hline $\begin{array}{c}\text { Biaya } \\
\text { Investasi/mesin (Rp) }\end{array}$ & $\begin{array}{c}\text { Biaya komponen } \\
\text { otomatis Listrik (Rp) }\end{array}$ & $\begin{array}{l}\text { Biaya Elemen } \\
\text { listrik (Rp) }\end{array}$ & $\begin{array}{l}\text { Efisiensi biaya } \\
\qquad(\mathrm{Rp})\end{array}$ \\
\hline 25.000 .000 & 4.500 .000 & 500.000 & 20.000 .000 \\
\hline \multicolumn{4}{|c|}{ Tabel 11 Tabel perincian total biaya Alternatif 13} \\
\hline $\begin{array}{l}\text { Efisiensi biaya } \\
\qquad(\mathrm{Rp})\end{array}$ & $\begin{array}{cc}\text { Biaya Energi/ } & \text { Biaya perawatan/ } \\
\text { Hari (Rp) } & \text { hari (Rp) }\end{array}$ & $\begin{array}{c}\text { Biaya } \\
\text { Komponen (Rp) }\end{array}$ & $\begin{array}{l}\text { Total Biaya } \\
\text { (Rp) }\end{array}$ \\
\hline 20.000 .000 & 18.000 & 4.000 .000 & 24.020 .900 \\
\hline \multicolumn{4}{|c|}{ Tabel 12 Tabel perincian total biaya Alternatif 15} \\
\hline $\begin{array}{c}\text { Biaya } \\
\text { Investasi/mesin (Rp) }\end{array}$ & $\begin{array}{cc}\text { Biaya komponen } & \mathrm{B} \\
\text { otomatis Listrik }(\mathrm{Rp}) & \\
\end{array}$ & $\begin{array}{l}\text { Biaya Elemen } \\
\text { listrik }(\mathrm{Rp})\end{array}$ & $\begin{array}{l}\text { Efisiensi biaya } \\
(\mathrm{Rp})\end{array}$ \\
\hline 25.000 .000 & 4.500 .000 & 500.000 & 20.000 .000 \\
\hline \multicolumn{4}{|c|}{ Tabel 13 Tabel perincian total biaya Alternatif 15} \\
\hline $\begin{array}{l}\text { Efisiensi biaya } \\
(\mathrm{Rp})\end{array}$ & $\begin{array}{cc}\text { Biaya Energi/ } & \text { Biaya Perawatan/ } \\
\text { Hari }(\mathrm{Rp}) & \text { hari }(\mathrm{Rp}) \\
\end{array}$ & $\begin{array}{c}\text { Biaya } \\
\text { Komponen (Rp) }\end{array}$ & $\begin{array}{c}\text { Total Biaya } \\
(\mathrm{Rp})\end{array}$ \\
\hline Rp 20.000.000 & $\mathrm{Rp} 18.000$ & $\mathrm{Rp} 4.378 .000$ & Rp.24.398.900 \\
\hline
\end{tabular}

Tabel 14 Tabel rekapitulasi perincian biaya operasional mesin alternatif 1,3,7,8,13,dan 15 selama 5 tahun

\begin{tabular}{lcc}
\hline Mesin & $\begin{array}{c}\text { Biaya total } \\
\text { operasional } \\
\text { (Rp/Hari) }\end{array}$ & $\begin{array}{c}\text { Biaya Total }(5 \\
\text { Tahun) }\end{array}$ \\
\hline Mesin desain & 27.450 & $\mathbf{4 9 . 4 1 0 . 0 0 0}$ \\
Awal & 29.519 & $\mathbf{5 3 . 1 3 4 . 2 0 0}$ \\
Alternatif 1 & 29.519 & $\mathbf{5 3 . 1 3 4 . 2 0 0}$ \\
Alternatif 3 & 31.292 & $\mathbf{5 6 . 3 2 5 . 6 0 0}$ \\
Alternatif 7 & 31.292 & $\mathbf{5 6 . 3 2 5 . 6 0 0}$ \\
Alternatif 8 & 20.900 & $\mathbf{3 7 . 6 2 0 . 0 0 0}$ \\
Alternatif 13 & 20.900 & $\mathbf{3 7 . 6 2 0 . 0 0 0}$ \\
Alternatif 15 &
\end{tabular}

Tabel 16 Besarnya performansi setiap alternatif

\begin{tabular}{clc}
\hline No & Alternatif Rancangan & Performansi \\
\hline 1 & Mesin Awal & 264 \\
2 & Alternatif 1 & 302 \\
3 & Alternatif 3 & 314 \\
4 & Alternatif 7 & 265 \\
5 & Alternatif 8 & 263 \\
6 & Alternatif 13 & 295 \\
7 & Alternatif 15 & 291 \\
\hline
\end{tabular}

\section{Kekurangan dan Kelebihan} Alternative Rancangan

Setelah melakukan analisa dari beberapa alternative rancangan mulai dari biaya operasional, pembobotan dengan AHP (Devendra Singh Verma and Ajitabh pateriya, 2013)

\section{Langkah Rekomendasi}

Pada langkah rekomendasi didasarkan pada beberapa perhitungan dan penilaian performansi dan nilai (value).

Perhitungan Performansi dalam makalah ini didasarkan pada Biaya, Kualitas Produk, Kemudahan proses, dan Kinerja pemerataan suhu 
Tabel 15 Kekurangan dan kelebihan dari masing-masing alternative ditampilkan dengan tabel berikut

\begin{tabular}{|c|c|c|}
\hline Alternatif & Kelebihan & Kekurangan \\
\hline Mesin awal & $\begin{array}{l}\text { Waktu proses pematangan lebih } \\
\text { cepat, kemudahan proses bagi } \\
\text { operator. } \\
\text { Untuk pemerataan suhu biaya } \\
\text { investasi yang dibutuhkan } \\
\text { lebih murah }\end{array}$ & $\begin{array}{l}\text { Harga mahal, Biaya investasi dan } \\
\text { biaya perawatan mesin mahal jika } \\
\text { dibandingkan } \\
\text { dengan alternatif } 1 \text { dan alternatif } 2 . \\
\text { Harga listrik PLN mahal }\end{array}$ \\
\hline Alternatif 1 & $\begin{array}{l}\text { Biaya investasi pada sumber } \\
\text { energi lebih murah jika } \\
\text { dibandingkan dengan mesin } \\
\text { alternatif } 3 \text {, alternatif } 13 \text { dan } \\
\text { alternatif } 15 \\
\text { Gas mudah didapatkan dipasaran } \\
\text { Kemudahan proses pada mesin } \\
\text { baik dari prosess perawatan dan } \\
\text { proses menjalankan mesin. }\end{array}$ & $\begin{array}{l}\text { Biaya perawatan mesin per hari masih } \\
\text { mahal jika dibandingkan dengan } \\
\text { alternatif } 3 \text { dan desain awai } \\
\text { Biaya operasional mesin selama } 5 \\
\text { tahun mahal. } \\
\text { Tidak terdapat pipa sebagai } \\
\text { pendistribusian suhu pada tiap level } \\
\text { rak mesin }\end{array}$ \\
\hline Alternatif 3 & $\begin{array}{l}\text { Biaya investasi pada sumber } \\
\text { energi cukup murah. } \\
\text { Gas mudah didapatkan dipasaran } \\
\text { Kemudahan dalam menjalankan } \\
\text { proses mesin dan proses } \\
\text { perawatan }\end{array}$ & $\begin{array}{l}\text { Biaya perawatan mesin per hari masih } \\
\text { mahal jika dibandingkan dengan } \\
\text { alternatif } 3 \text { dan desain awal } \\
\text { Biaya operasional mesin selama } 5 \\
\text { tahun mahal. } \\
\text { Biaya komponen lebih mahal jika } \\
\text { dibandingkan dengan alternatif } 1\end{array}$ \\
\hline Alternatif 7 & $\begin{array}{l}\text { Biaya investasi pada sumber } \\
\text { energi cukup murah. } \\
\text { Biaya operasional mesin selama } \\
5 \text { tahun sangat murah } \\
\text { Kemudahan operasi pada mesin } \\
\end{array}$ & $\begin{array}{l}\text { Biaya perawatan mesin sangat mahal. } \\
\text { Mitan sulit didapatkan dipasaran } \\
\text { Kualitas hasil mesin sangat rendah }\end{array}$ \\
\hline Alternatif 8 & $\begin{array}{l}\text { Biaya investasi pada sumber } \\
\text { energi cukup murah. } \\
\text { Adanya alat ditribusi suhu mesin }\end{array}$ & $\begin{array}{l}\text { Biaya perawatan mesin sangat mahal. } \\
\text { Biaya operasional mesin selama } 5 \\
\text { tahun sangat mahal jika dibandingkan } \\
\text { dengan } \\
\text { alternatif } 7 \text {. } \\
\text { Mitan sulit didapatkan dipasaran }\end{array}$ \\
\hline Alternatif 13 & $\begin{array}{l}\text { Biaya Energi dan biaya } \\
\text { perawatan yang dibutuhkan } \\
\text { perhari lebih murah } \\
\text { Perawatan Mesin mudah } \\
\text { dilakukan } \\
\text { Kemudahan proses bagi operator. }\end{array}$ & $\begin{array}{l}\text { Harga mahal } \\
\text { Biaya komponen mesin mahal } \\
\text { Biaya yang dikeluarkan untuk } \\
\text { investasi mesin cukup tinggi } \\
\text { Perlu pengawasan ekstra agar lebih } \\
\text { hati-hati dalam pengunaannya }\end{array}$ \\
\hline Alternatif 15 & $\begin{array}{l}\text { Biaya Energi dan biaya } \\
\text { perawatan yang dibutuhkan } \\
\text { perhari lebih murah } \\
\text { Perawatan Mesin mudah } \\
\text { dilakukan } \\
\text { Kemudahan proses bagi operator. } \\
\text { Terdapat pipa sebagai } \\
\text { pedistribusi suhu dalam setiap } \\
\text { level rak mesin }\end{array}$ & $\begin{array}{l}\text { Harga mahal } \\
\text { Biaya yang dikeluarkan untuk } \\
\text { investasi mesin cukup tinggi } \\
\text { Perlu pengawasan ekstra agar } \\
\text { lebih hati-hati dalam pengunaannya }\end{array}$ \\
\hline
\end{tabular}


Tabel 17 Hasil pembobotan dan performansi

\begin{tabular}{llcc}
\hline No & Alternatif Rancangan & Pn & Rangking \\
\hline 1 & Mesin Awal & 30.910 & $\mathbf{7}$ \\
2 & Alternatif 1 & 41.003 & $\mathbf{1}$ \\
3 & Alternatif 3 & 40.921 & $\mathbf{2}$ \\
4 & Alternatif 7 & 36.015 & $\mathbf{6}$ \\
5 & Alternatif 8 & 36.073 & $\mathbf{5}$ \\
6 & Alternatif 13 & 37.324 & $\mathbf{3}$ \\
7 & Alternatif 15 & 37.300 & $\mathbf{4}$ \\
\hline
\end{tabular}

Tabel 18 Perbandingan setiap alternatif dengan mesin yang telah ada

\begin{tabular}{llllllll}
\hline No & Alternatif & Pn & Cn & & Value & Rating & Konstanta \\
& Rancangan & & & & & & \\
\hline 1 & Mesin Awal & 30.910 & 25.027 .450 & 0.000001235 & $\mathbf{1}$ & $\mathbf{7}$ & $\mathbf{8 0 9 6 8 7 . 8 0 3 3}$ \\
2 & Alternatif 1 & 41.003 & 22.029 .517 & 0.000001861 & 1.507 & $\mathbf{1}$ & \\
3 & Alternatif 3 & 40.921 & 22.407 .517 & 0.000001826 & 1.479 & $\mathbf{2}$ & \\
4 & Alternatif 7 & 36.015 & 21.381 .292 & 0.000001684 & 1.364 & $\mathbf{3}$ & \\
5 & Alternatif 8 & 36.073 & 21.633 .292 & 0.000001667 & 1.350 & $\mathbf{4}$ & \\
6 & Alternatif 13 & 37.324 & 24.020 .900 & 0.000001554 & 1.258 & $\mathbf{5}$ & \\
7 & Alternatif 15 & 37.300 & 24.398 .900 & 0.000001529 & 1.238 & $\mathbf{6}$ & \\
\hline
\end{tabular}

Setiap nilai performansi dikalikan dengan pembobotan yang diperoleh dengan pendekatan AHP dan ditampilkan dengan tabel diatas.

Perhitungan Nilai, Perhitungan nilai diperoleh dari performansi dibagi dengan jumlah biaya (Ryosuke ANDO, 2005; Rahim Aminzadeha, 2011). Nilai (value) setiap alternatif dibandingkan (Soumi Ghosh, et. al, 2012) dengan nilai mesin yang sudah ada, sehingga hasilnya disajaikan dalam tabel.

Perbandingan nilai tertinggi yaitu alternatif 1dengan perbandingan nilai 1.507 dan permformansi 41.003. Alternatif yang terbaik yaitu alternatif 1 .

\section{ANALISA}

\section{Analisa penilaian tiap criteria}

Berdasarkan penilaian ketiga orang pakar (Yu-Lung Hsu et. al., 2010) pada tiap kriteria dan sub kriteria maka didapatkan nilai dari rata-rata bobot tiap kriteria dan sub criteria tersebut yaitu :

1. Biaya $=0,458$

- $\quad$ Biaya Konsumsi Energi = 0,206

- Biaya Investasi $=0,114$

- Biaya Perawatan $=0,137$

2. Kualitas Hasil $=0,196$

- Roti Rusak =0,096

- Roti Tidak Matang $=0,044$

- Roti Beresidu =0,56
3. Kemudahan Proses $=0,202$

- Perawatan Mesin =0,028

- Proses menjalankan Mesin =0,174

4. Kinerja $=0,143$

- Kestabilan Suhu $=0,067$

- Distribusi suhu didalam mesin = 0,048

- Kecepatan Mencapai suhu yang diinginkan $=0,028$

\section{Analisa Performansi}

Analisa performansi menunjukkan function (performance benefit) yang dihitung dari penialian perceptual based performance. Dari perhitungan performansi maka didapatkan nilai performansi terbobot dari tiap alternative yang dimunculkan dan berdasarkan hasil perangkingan nilai performansinya maka didapatkan alternative 1 sumber energi gas sistem otomatis tanpa pipa sebagai alternative yang mempunyai performansi tertinggi yaitu 41,003, alternative 3 sumber energi gas sistem otomatis dengan menggunakan 6 pipa sebesar 40,921, alternative 7 sumber energi mitan sistem otomatis tanpa pipa sebesar 36,015, alternative 8 sumber energi mitan sistem otomatis dengan 4 pipa sebesar 36,073, alternatif 13 sumber energi listrik-gas sistem otomatis tanpa pipa sebesar 37,324, alternative 15 sumber energi listrik-gas sistem otomatis dengan 6 
pipa sebesar 37,300, dan mesin awal dengan nilai performansi terendah sebesar 30,910 .

\section{Analisa Value}

Analisa value menunjukkan nilai suatu alternatif yang dihitung dari perbandingan antara performansi dan biaya. Alternatif yang memiliki value tertinggi akan menjadi alternatif terbaik yang direkomendasikan. Berdasarkan perumusan perhitungan value, dengan menggunakan perbandingan performansi tiap alternatif dengan mesin awal dan biaya yang dibutuhkan didapatkan Alternatif 1 yaitu mesin fermentasi yang menggunakan sumber energi gas sistem otomatis tanpa pipa sebagai alternative terbaik dengan value terbesar yaitu 1,507 dengan performance sebesar 41.003 dan biaya sebesar Rp 22.029.517,- jika dibandingkan dengan alternative yang lainnya. Jadi pemilihan alternative terbaik untuk mesin fermentasi roti ini adalah dipilih alternatif 1 dengan menggunakan sumber energi gas yang ada sistem otomotis tanpa menggunakan pipa.

\section{KESIMPULAN}

Berdasarkan hasil perhitungan value (nilai) didapatkan alternatif 1, yaitu mesin fermentasi dengan sumber energi gas sistem otomatis tanpa pipa, sebagai alternatif terbaik dengan nilai ,507. Nilai ini diperoleh dari performansi sebesar 41.003 dan biaya sebesar $\operatorname{Rp} 22.029 .517$,-

Mesin fermentasi terbaik yang direkomendasikan dari hasil penelitian ini adalah mesin fermentasi sistem otomatis tanpa menggunakan pipa yang ditambahkan untuk pemerataan distribusi suhu. Sehingga hasil penelitian ini tidak menjawab perumusan masalah kedua yang ingin dipecahkan.

\section{DAFTAR PUSTAKA}

1. Amit Sharma, Harshit Srivastava, Andr.M.Belokar, 2011, A Case Study Analysis Through The Implementation Of Value Engineering, International Journal Of Engineering Science And Technology (IJEST), Vol. 3 No. 3 March 2204-2213
2. Arazi Idrus And Christiono Utomo, 2010, Functionality Of Negotiation Agent On Value-Based Design Decision, World Academy Of Science, Engineering And Technology 39, 394398

3. Boo Young Chung, Syadaruddin Syachrani, Hyung Seok (David) Jeong, And Young Hoon Kwak, 009, Applying Process Simulation Technique To Value Engineering Model: A Case Study Of Hospital Building Project, IEEE Transactions On Engineering Management, Vol. 56, No. 3, August, 549-559

4. Chougule M.A. And Kallurkar S.P, 2012, Use Of Value Analysis Technique For Cost Reduction In Production Industry -A Case Study, International Journal Of Engineering Science And Technology (IJEST), Vol. 4 No.05 May, 2101-2114

5. Chougule Mahadeo Annappa \& Kallurkar Shrikant Panditrao, 2013, Optimization of Furniture Product in Furniture Industry by Using Value Engineering with Function Analysis, Function Evaluation and Decision Matrix- A Case Study, International Journal of Application or Innovation in Engineering \& Management (IJAIEM), Volume 2, Issue 3, March, 55-64

6. Jahangir Yadollhi Farsi, Noraddin Hakiminezhad, 2012, The integration of QFD Technique, Value Engineering and Design for Manufacture and Assembly (DFMA) during the Product Design Stage. Advances in Environmental Biology, 6(7): 2096-2104

7. J. Cerqueiro, L. López, and J. Pose, 2011, A proposal to incorporate the Value Analysis/Value Engineering techniques into a PLM syste, Proceedings of the IMProVe 2011International conference on Innovative Methods in Product Design June 15th -17 th, 2011, Venice, Italy, 140-149 
8. Habibollah Najafi and Amir Abbas Yazdani, 2011, Value Engineering And Its Effect In Reduction Of Industrial Organization Energy Expenses World Academy Of Science, Engineering And Technology 49 235-241

9. Houshang Taghizadeh, Hassan Taheri, And Abdolhossein Shokri, 2012, The Study Of The Effective Organizational Factors In The Execution Of Value Engineering, International Journal Of Innovation, Management And Technology, Vol. 3, No. 3, June 202205

10.Rahim Aminzadeha, Amirruddin Ismailb, and Ishak Arshad, Development Value Engineering Modeling in Construction Transportation, Australian Journal of Basic and Applied Sciences, 5(12): 397-402
11.Soumi Ghosh, Sanjay Kumar Dubey, and Ajay Rana, Object Oriented Softwaresystem Based On AHP, International Journal on Computer Science and Engineering (IJCSE), Vol. 4 No. 11 Nov , 1848-1853

12.Ryosuke Ando, 2005, Evaluation For Improvement Plan Of Highways By Applying Value Engineering, Journal of the Eastern Asia Society for Transportation Studies, Vol. 6, pp. 1021 $-1035$

13.Yu-Lung Hsu A, Cheng-Haw Lee A, and V.B. Kreng, 2010, The Application Of Fuzzy Delphi Method And Fuzzy AHP In Lubricant Regenerative Technology Selection, Expert Systems With Applications 37 (2010) 419-425 